\title{
Aortic Thromboembolism in a Cat
}

\author{
Renata Andrade Silva', Tábata Torres Megda', Gabriela Ferreira Siano², Fernanda dos Santos Alves ${ }^{3}$, \\ Suzane Lilian Beier ${ }^{4}$, Bruno Henrique de Albuquerque Paiva ${ }^{5}$ \& Ana Patrícia de Carvalho da Silva ${ }^{6}$
}

\begin{abstract}
Background: The aortic thromboembolism in cats is usually associated with cardiomyopathy, when a thrombus or a clot is formed in the heart, transported through the bloodstream and fixed at somewhere. According to Virchow's triad, changes in the endocardial surface or in the blood flow/composition can result in thrombus formation. The most common clinical signs are: hind limb paralysis, lack of femoral pulse, cold and cyanotic extremities. The treatment should be performed as soon as possible and it is based on antiplatelet agents, anticoagulants, thrombolytics agents or surgical procedures. It is reported the case of a cat presenting aortic thromboembolism.

Case: Macroscopically it was observed that the hind limb extremities were with a dark red color and with a bad odor on cut. There were in the subcutaneous tissue of the hind limbs a severe and diffuse accumulation of a reddish material, translucent, shiny, gelatinous (intense diffuse edema) and the skeletal muscles of the hind limbs had extensive pale and friable areas. Inside the medial saphenous vein lumen there was a greyish-white and soft material which adhered to the vessel wall. The lungs were not fully collapsed, it had a smooth and shiny surface and an extensive dark red area in the right middle lobe (moderate extensive bleeding). The spleen was with slightly bulging edges and on cut flowed moderate amount of blood (moderate congestive splenomegaly). In the kidneys there was numerous whitish and slightly depressed areas measuring approximately $0.5 \mathrm{~cm}$ in diameter, which was deep and wedge-shaped on cut (multifocal infarction). Microscopically it was observed mild diffuse congestion in the spleen; mild diffuse congestion and moderate focal bleeding in the lungs; intense multifocal neutrophilic infiltrate associated with coagulation necrosis in the cortical and medullary with multifocal cysts in moderate amounts in the kidneys; abdominal aorta artery with intense accumulation of fibrin, red blood cells and cellular debris organized and stuck in the tunica intima featuring a multifocal thrombosis area. The saphenous artery contained fibrin organization in the lumen, which was compatible with embolus.

Discussion: The patient presented paralysis of hind limbs, absence of superficial and deep pain, cyanotic and cold hind limb extremities, loss of proprioception of the limbs and absence of detectable pulse in the vascular Doppler, which is characteristic of thromboembolic disease, but no specific sign of the underlying cause. Thromboembolic episodes are compatible with thrombus in the trifurcation of the abdominal aorta artery and the embolus in the saphenous artery. The focal lung bleeding can be the clinical sign of pulmonary thromboembolism. The unilateral renal infarction may have been induced after surgical excision of the thrombus, as the patient had no change in renal biochemical parameters prior to the surgical procedure. This is a complication, because small thrombus fragments can break off and cause thromboembolism elsewhere. The surgical procedure is generally non indicated because most domestic cats that have arterial thrombus have significant heart disease and more than half have congestive heart failure, making them poor candidates for surgery, which did not occur in the clinical case described. The repetitions of the events are common, and significant embolization of the kidney, intestines or other organs worsen the prognosis.
\end{abstract}

Keywords: aortic thromboembolism, feline. 


\section{INTRODUCTION}

The aortic thromboembolism is a syndrome that occurs in cats and it is generally associated with heart disease and all forms of cardiomyopathy predispose to risk. This thrombus follows the systemic circulation and more than $90 \%$ of the cases it installs at the trifurcation of the caudal aorta [14].

The syndrome tends to occur when changes in normal hemostatic processes creates conditions that promote clot formation or damage the thrombolysis. The three processes that may promote thrombosis are called Virchow Triad, namely: changes in endothelial surface; in the bloodstream or in the blood composition $[2,5,11,14]$.

Clinical signs in the limbs can be characterized by the 5 P's: acute paresis, pain, femoral arterial pulses not palpable or weak and heat loss in the distal portion of the affected limbs. The extremities can be cold and pale, but it is variable because the cat may have pallor or cyanosis in the limbs depending on the degree of ischemia $[11,12,14]$.

It is an acute and infrequent disease, the treatment can be surgical or clinical with the use of anticoagulants or thrombolytics. Both treatments should be performed as soon as possible to increase the chances of cure. However, the prognosis is still considered unfavorable [4].

The study aimed to report a case of arterial thromboembolism in a feline, but this cat did not have heart disease, the main cause of arterial thromboembolism.

\section{CASE}

A male, adult, mixed-breed domestic cat was admitted to the Veterinary Hospital of the Veterinary School presenting difficulty in walking with the hind limbs and severe pain, according to reports of the owner. Physical examination revealed adequate nutritional status, mucous with normal color, normal heart rate $(180 \mathrm{bpm})$, tachypnea $(60$ mpm), normothermia, eigth percent of dehydration, severe pain in the gastrocnemius muscle region, cyanotic and cold extremities of the hind limbs (Figure 1) and absence of bilateral peripheral pulse checked with vascular Doppler. With these clinical signs it was suspected of a case of aortic thromboembolism.

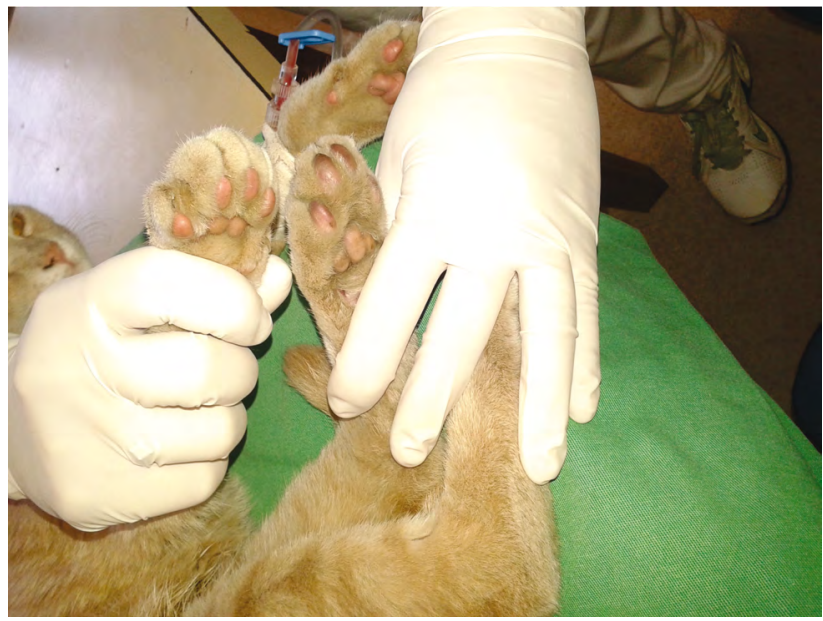

Figure 1. Note the different color between fore limbs and hind limbs. The extremities of the fore limb are pink and the pelvic member are with cyanotic extremities (Source: Personal Archive).

It were requested $\mathrm{X}$-rays, abdominal ultrasonography with color flow using Doppler, echocardiography, complete blood count, biochemical tests (urea, creatinine, APTT, PTT, alkaline phosphatase, total and fractionated proteins), total T4 and blood gas analysis .

It wasn't observed cardiac alterations in radiography and in the echocardiography, but the chest radiograph revealed increased radiopacity in the right middle lobe of the lung. During abdominal ultrasonography with color flow using Doppler was observed absence of blood flow in the caudal abdominal aorta and the presence of a hyperechoic structure, no forming of acoustic shadow, immediately cranial to the trifurcation of the abdominal aorta (Figure 2).

Among the clinicopathological findings there was elevated BUN values $(71 \mathrm{mg} / \mathrm{dL}$; reference value: 10.0 to 30.0$)$ and thrombocytopenia $\left(101,000 / \mathrm{mm}^{3}\right.$; reference value: $300,000-800,000$ ).

During the days of hospitalization were administered: morphine $10 \mathrm{mg} / \mathrm{mL}\left(\text { Dimorf }^{\circledR}\right)^{1}$, IM $(0.3 \mathrm{mg} /$ $\mathrm{kg}$ ), cephalothin $1 \mathrm{~g} / 5 \mathrm{~mL}, \mathrm{IV}(30 \mathrm{mg} / \mathrm{kg}$ ) [Cefalotina Sódica $\left.{ }^{\circledR}\right]^{2}$, heparin 5,000 IU/mL (Hemofol $\left.{ }^{\circledR}\right)^{1}$, SC (200 $\mathrm{IU} / \mathrm{kg}$ ), fluid therapy with lactate ringer (IV) and it was provided food (Hill's a/d $\left.{ }^{\circledR}\right)^{3}$ and water.

On the third day of hospitalization was performed an arteriotomy, but the blood flow of the pelvic limbs was not re-established and began the upward necrosis of the pelvic limbs. Due to the unfavorable prognosis was chosen euthanasia, and the patient was sent on the same day for necropsy in the Veterinary Pathology Laboratory. 
In the macroscopy it was observed that the hind limb extremities were with a dark red color and with a bad odor on cut. There were in the subcutaneous tissue of the hind limbs a severe and diffuse accumulation of a reddish material, translucent, shiny, gelatinous (intense diffuse edema) and the skeletal muscles of the hind limbs had extensive pale and friable areas. In the medial saphenous vein lumen there was a greyish-white and soft material which adhered to the vessel wall.

During the necropsy were collected fragments of saphenous arteries, abdominal aorta, spleen, lung and kidney for histopathological examination. This material was fixed in $10 \%$ formalin for $24 \mathrm{~h}$, followed by dehydration in increasing alcohol, diaphanization

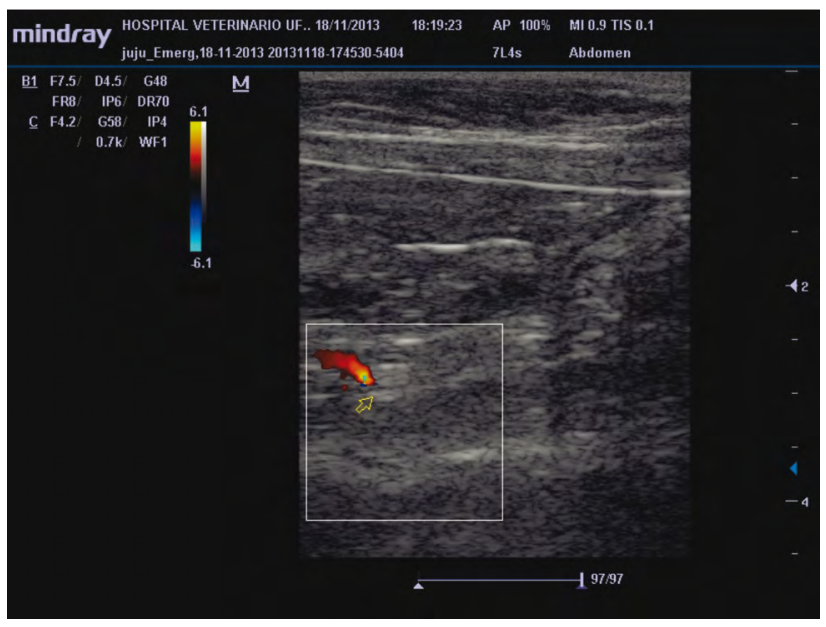

Figure 2. During abdominal ultrasonography with color flow using Doppler could be observed that the blood flow stopped in the abdominal aorta proximal to its trifurcation; the arrow identifies the thrombus (Source: Personal Archive).

\section{DISCUSSION}

Clinical signs can already take the veterinarian to make a primary diagnosis. The lack of blood flow causes paralysis of the hind limbs, absence of superficial and deep pain, loss of proprioception of the limbs, absence of femoral pulse, pallor of the affected extremities or nail beds, cyanotic and cold extremities [5].

The respiratory rate is obviously higher in most cats with arterial thromboembolism and, in some cases, the pattern is also changed with panting animals [14]. This can be attributed to severe pain in the region of the gastrocnemius muscle. Thrombocytopenia was possibly caused by troublesome blood collection, causing platelet aggregates and/or splenic sequestration. The high urea and creatinine standard value can be caused by reduced urinary flow (prerenal azotemia), which occurs in cases of dehydration. in xylol and paraffin embedding. The fragments were cut into $5 \mu \mathrm{m}$ and stained with hematoxylin and eosin for histopathological evaluation.

In the microscopy was observed mild diffuse congestion in the spleen; mild diffuse congestion and moderate focal bleeding in the lungs; intense multifocal neutrophilic infiltrate associated with coagulation necrosis in the cortical and medullary with multifocal cysts in moderate amounts in the kidneys; abdominal aorta artery with intense accumulation of fibrin, red blood cells and cellular debris organized and stuck in the tunica intima featuring a multifocal thrombosis area. The saphenous artery contained fibrin organization in the lumen, which was compatible with embolus (Figure 3).

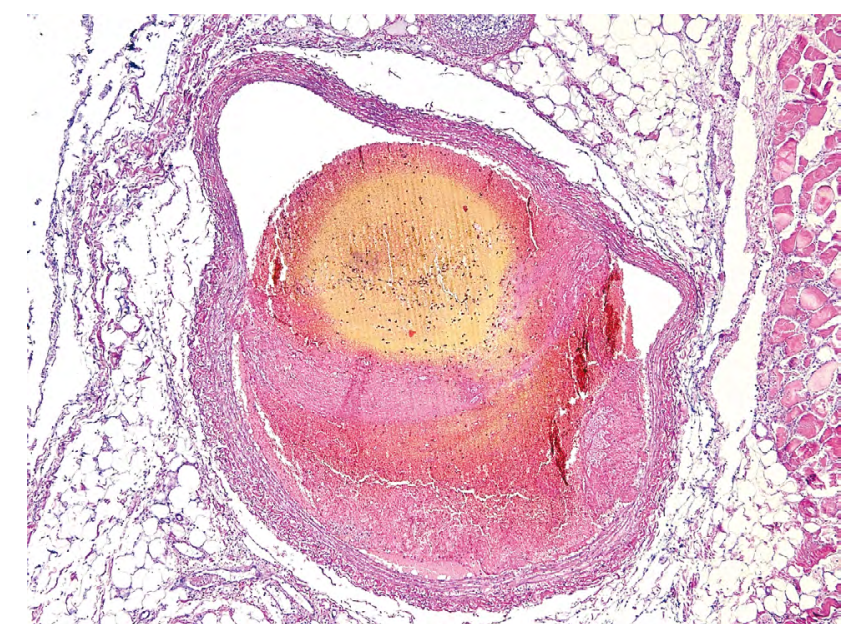

Figure 3. Thrombosis in abdominal aorta. Magnification 100x. (Image courtesy of Animal Pathology Laboratory EV- UFMG).

Increased radiopacity over the right medium lung lobe topography, which was confirmed by histopathological examination as a moderate extensive bleeding, was possibly caused by pulmonary thromboembolism. In some cases of pulmonary thromboembolism, the lungs appear normal, when changes occur in chest radiographs the caudal lobes are the most affected and it can end in focal opacities, interstitial or alveolar pattern resulting from bleeding or edema [2]. An imaging tool useful to visualize blood flow in the abdominal aorta is the abdominal ultrasound with color flow using Doppler [12]. During the examination it was observed absence of blood flow in the caudal abdominal aorta and the presence of a hyperechoic structure, no forming acoustic shadow, immediately cranial to the trifurcation of the abdominal aorta, with conformation compatible with arterial thrombus. 
The prescribed treatment was intended to keep the patient hydrated, eliminate secondary contamination, prevent the formation of new thrombi and perform the control of pain. The support treatment given improved the quality of life of the animal, but the surgical procedure does not re-established blood flow in the pelvic limbs.

The administration of heparin is indicated for limiting the extent of the existing thrombus and prevention of other thromboembolic episodes. Its use has been based on the premise that, by delaying the synthesis of coagulation factors or for accelerating its inactivation can be prevented thrombosis resulting from activation of blood coagulation pathways. Heparin acts by binding to antithrombin III, favoring their ability to neutralize the activated factors XII, XI, X, IX and thrombin. This prevents the activation of the clotting process [14].

During the treatment, the activated partial thromboplastin time (APTT) of the patient should be monitored, but the results will not accurately tell the serum concentrations of heparin. Before starting the treatment, coagulation tests should be conducted to have a baseline to compare and control during the treatment, being the goal of the therapy to increase the APTT 1.5 to 2.5 from baseline $[11,14]$.

Low molecular weight heparins are safer because it has a smaller size and cannot bind simultaneously on thrombin and antithrombin. It is more effective against factor Xa. These substances have little ability to inhibit thrombin, therefore cause less bleeding. Low molecular weight heparins are less bound to plasma proteins, the endothelial cells and macrophages when administered subcutaneously compared to unfractionated heparin, so it has higher availability and longer half-life. This heparin doesn't significantly affect clotting times, so the monitoring of APTT is unnecessary $[1,11,14]$.

According to Ware [14], the surgery is usually contraindicated, since the majority of the domestic cats that present arterial thrombus have significant heart disease and more than a half have congestive heart failure, making them poor candidates for surgery, which didn't occur in the clinical case described. The use of an embolectomy catheter for clot removal was not very effective in cats [11]. A study of percutaneous mechanical thrombectomy in cats with arterial thromboembolism in the distal aorta reported that half of the cats survived [9]. The percutaneous mechanical thrombectomy is a specialized technique involving mechanical thrombolysis by fluoroscopy and removal of the thrombus via an arterial catheter [4].

Thrombolytic drugs may be used to try to dissolve the thrombus, but starting $4 \mathrm{~h}$ after thrombus formation to maximize the success of the therapy [10]. According to Litwak [7], surgical excision of the embolus is a treatment for thromboembolism. However, this same author emphasizes that the procedure has a higher success rate when performed within $6 \mathrm{~h}$ after the formation of thrombus.

In cats considered susceptible to thromboembolic disease, commonly is used as prophylactic treatment the antiplatelet drugs or anticoagulants.

In the case reported, the surgical procedure was performed on the third day of hospitalization which dramatically reduced the chance of success postoperatively. This case depicts a common frame of arterial thromboembolism where the underlying cause has not been discovered. The cause of thromboembolism should be the target of incessant research, so the specific treatment can be started quickly.

One factor that supports occasional reports of arterial thromboembolism in cats is the possibility of inherited or acquired hypercoagulable where complete diagnostic assessments do not identify the underlying disease. A genetic abnormality of clotting may explain this idiopathic thrombosis [11].

The aortic thromboembolism in cats is easy to diagnose because this is mostly done from the clinical signs, which are classic. The prognosis is guarded to poor. The treatment should be performed as soon as possible to prevent any serious complications due to ischemia caused by lack of blood circulation in the affected areas. The prophylactic treatment may be used to avoid the risk of development of new thrombi. The discovery of the primary causes of thromboembolism is extremely important since it can prevent the formation of systemic thrombus.

A therapy that satisfies the removal of thrombus surgically with the use of drugs that prevent the formation of new clots causing the least possible side effects seems the best option. But for this, more research is needed in this area.

\section{MANUFACTURERS}

${ }^{1}$ Cristália Produtos Químicos Farmacêuticos. Itapira, SP, Brazil.

${ }^{2} \mathrm{ABL}$ Antibióticos do Brasil. Indianápolis, SP, Brazil.

${ }^{3}$ Hill's Pet Nutrition. São Paulo, SP, Brazil.

Declaration of interest. The authors report no conflicts of interest. The authors alone are responsible for the contents and writing of the paper. 


\section{REFERENCES}

1 Alwood A.J., Downend A.B., Brooks M.B., Slensky K.A., Fox J.A., Simpson S.A., Waddell L.S., Baumgardner J.E. \& Otto C.M. 2007. Anticoagulant effects of low-molecular-weight heparins in healthy cats. Journal of Veterinary Internal Medicine. 21(Suppl 3): 378-387.

2 Couto C.G. 2010. Distúrbios do Sistema Respiratório. In: Nelson R.W. \& Couto C.G. (Eds). Medicina Interna de Pequenos Animais. 4.ed. Rio de Janeiro: Elsevier, pp.316-318.

3 Defrancesco T.C. 2003. Tromboembolismo aórtico. In: Tilley L.P. \& Smith Junior F.W.K. (Eds). Consulta Veterinária em 5 minutos: espécie canina e felina. 2.ed. São Paulo: Manole, pp.59-61.

4 Dunn M.E. 2011. Thrombectomy and thrombolysis: the interventional radiology approach. Journal of the Veterinary Emergency and Critical Care. 21(Suppl 2): 144-150.

5 Fox P.R. 2004. Miocardiopatias felinas. In: Ettinger S.J. \& Feldman E.C. (Eds). Tratado de Medicina Interna Veterinária - Doenças do Cão e do Gato. 5.ed. Rio de Janeiro: Guanabara Koogan, pp.968-972.

6 Koyama H., Matsumoto H., Fukushima R. \& Hirose H. 2010. Local Intra-Arterial Administration of Urokinase in the Treatment of a Feline Distal Aortic Thromboembolism. Journal of Veterinary Medical Science. 72(Suppl 9): 12091211.

7 Litwak P.1993. Peripheral vascular procedures and disorders. In: Slatter D. (Ed). Textbook of Small Animal Surgery. 3rd edn. Philadelphia: Saunders, pp.922-929.

8 Moore K.E., Morris N., Dhupa N., Murtaugh R.J \& Rush J.E. 2000. Retrospective study of streptokinase administration in 46 cats with arterial thromboembolism. Journal of the Veterinary Emergency and Critical Care. 10(Suppl 4): 245-257.

9 Reimer S.B., Kittleson M.D. \& Kyles A.E. 2006. Use of rheolytic thrombectomy in the treatment of feline distal aorta thromboembolism. Journal of Veterinary Internal Medicine. 20 (Suppl 2): 290-296.

10 Santos M.M. 2008. Principais condutas emergenciais no paciente com insuficiência cardíaca. In: Santos M.M. \& Fragata F.S. (Eds). Emergência e Terapia Intensiva Veterinária em Pequenos Animais. São Paulo: Roca, pp.272-283.

11 Smith S.A. \& Tobias A.H. 2004. Feline arterial thromboembolism: an update. Veterinary Clinics of North America: Small Animal Practice. 34(Suppl 5): 1245-1271.

12 Tilley L.P. Thromboembolic disease. 2011. In: Norsworthy G.D., Crystal M.A., Grace S.F. \& Tilley L.P. (Eds). The Feline Patient. 4th edn. Ames: Blackwell Publishing, pp.506-508.

13 Tobias A.H. \& Fine D.M. 2009. Arterial Thromboembolism in cats. In: Bonagura J.D. \& Twedt D.C. (Eds). Kirk's Current Veterinary Therapy XIV. 14th edn. St. Louis: Saunders Elsevier, pp.819-824.

14 Ware W.A. 2010. Doenças Miocárdicas do Gato. In: Nelson R.W. \& Couto C.G. (Eds). Medicina Interna de Pequenos Animais. 4.ed. Rio de Janeiro: Elsevier, pp.141-144.

15 Welch K.M., Rozanski E.A., Freeman L.M. \& Rush J.E. 2010. Prospective evaluation of tissue plasminogen activator in 11 cats with arterial thromboembolism. Journal of Feline Medicine and Surgery. 12(Suppl 2): 122-128 